\title{
THE ROLE OF COOPERATION FOR THE NEEDS OF BIOECONOMY DEVELOPMENT
}

\author{
Vilma Atkociuniene ${ }^{1}$, Aida Balkibayeva ${ }^{2}$ \\ ${ }^{1}$ Vytautas Magnus University Agriculture Academy, Lithuania \\ ${ }^{2}$ Saken Seifullin Kazakh AgroTechnical University, Kazakhstan \\ vilma.atkociuniene@vdu.lt
}

\begin{abstract}
The concepts of bioeconomy development require the integration of different sectors and economic activities. Bioeconomy helps to achieve the goals of sustainable development. This paper provides an overview of the cooperation for the need of bioeconomy development, examining it from agricultural cooperatives development, theoretical concept and European countries policy and Kazakhstan perspective. The research methods are induction and deduction, monographic, the group interview, statistical data analysis and synthesis, descriptive, matching and comparison and other methods. The cooperation passes through several levels of development - information, consultation, joint action, collective decision-making. The cooperation within farmers (horizontal cooperation) is so far narrow and limited to traditional cooperatives that bring together producers of the same product. New forms of cooperation and more diverse directions in national, regional and local levels are needed to develop the bioeconomy. Partnerships, the interdepartmental and interdisciplinary cooperation based on knowledge and innovation should be established between farmers, agri-food companies and scientific institutions, Kazakhstan and other countries universities. The agricultural and rural development advisory system should be improved, and new measures to promote communication, counseling and cooperation should be introduced.
\end{abstract}

Key words: cooperation, bioeconomy development, Kazakhstan.

\section{Introduction}

In order to achieve the goals of sustainable development, it is necessary to move towards a new way of economic growth, compatible with environmental protection and sustainable use of limited natural resources, while ensuring a significantly higher standard of living and reducing poverty (Bosman \& Rotmans, 2016; Lithuanian Bioeconomy..., 2017). One of the factors (key action) which has an influence to the development of bioeconomy, especially when bioeconomy is based on distributed economy model, discussed by P. Luoma, J. Vanhanen, P. Tommila (2011) is the cooperation. In this alternative strategy for the bioeconomy is an important argument that there is a need for the development of a global biobased economy and distributed production models at the local level. The distributed bio-based economy model is therefore - 'glocal' - both global and local. This distributed model is based on the fact that biomass cannot be easily or cheaply transported long distances. Instead, a distributed bioeconomy stresses the proximity both of the sites where raw material is acquired, and where goods and energy are produced and consumed. K. McCormick, N. Kautto (2013) identified that European Commission (2012) outlined key actions for a coherent bioeconomy enabled. One of them is strengthening cooperation at the international, national and regional levels.

The concept of cooperation has become broader and involves more forms of partnership and cooperation than the ordinary activities of traditional agricultural cooperatives. An essential problem of cooperation in Kazakhstan is that cooperation is not a value for the farmers and other stakeholders.
Therefore, the latter research aimed to understand the value of the cooperation, its benefits and aspects of its development, to analyse the state of cooperation in Kazakhstan.

The research object is role of cooperation between farmers and other rural stakeholders.

The research aim is to define the role of cooperation for the needs of bioeconomy development.

To achieve the aim, the following tasks were set: to analyse the theoretical preconditions for the development of bioeconomy and cooperation; to examine the trends of cooperation and agricultural cooperatives in Kazakhstan; to identified the networks and platforms for the needs of bioeconomy development in Kazakhstan.

The research methods are induction and deduction, monographic, the group interview, statistical data analysis and synthesis, descriptive, matching and comparison and other methods. Four group interviews (26 farm opinions) were organised after the training on agricultural issues in S. Seifullin Kazakh Agro Technical University. The interviews were carried out with the executives of profitably working private farms and agricultural companies as well as agricultural and rural development professionals, community organizations and non-government organization's leaders. The specific questions addressed: How can the cooperation between public authorities, farmers, researchers, extension services and market actors support a more sustainable (balanced) development? What are the characteristics of farmer's cooperation in the region? Are you aware of companies or farmers who are organizing activities under the principles of bioeconomy development? 


\section{Materials and Methods}

The paper is built on the analysis and synthesis of scientific literature which allow to describe the main terms of bioeconomy and cooperation. Several research methods were applied: monographic, descriptive, analysis and synthesis, induction and deduction.

'The Bioeconomy encompasses those parts of the economy that use renewable biological resources from land and sea to produce food, bio - materials, bio - energy and bio - products' (EU bioeconomy strategy, 2012). Bio-economy is a broad field ranging from agriculture, forestry, food and marine life to production of non-food materials, comprises several economic sectors, academic disciplines, and areas of policy. It is at the centre of several global and EU challenges in the near future such as the creation of growth and jobs, climate change, food security and resource depletion (Philippidis, M'barek, \& Ferrari, 2016). It is a cross-cutting issue having an effect on the whole society (Luoma, Vanhanen, \& Tommila, 2011). Bioeconomy helps society to meet the challenges that the EU and other countries face. One of the most important challenges is ensuring food security. The Rome Declaration on World Food Security in 1996 defined its three basic dimensions as: availability, accessibility and utilization, with a focus on nutritional well-being (Food and Agriculture Organization of the United Nations, 1996).

Managing natural resources sustainability and reducing dependence on non-renewable resources can only be overcome by developing the bioeconomy. For example, forest-based bioeconomy can contribute to climate change adaptation and mitigation. According the M. Lindner, M. Hanewinkel, G. Nabuurs (2017) findings measures that support active management and sustainable use for forests can contribute to the climate change adaptation and mitigation and bioeconomy development. The cooperation between the stakeholders and win-win solutions can ensure that forests remain stable and productive.

Most often, agricultural processing companies are located in cities. Concentration of jobs in cities and geographical mobility of labor force in rural areas poses a number of problems. Some rural areas are no longer able to carry out economic functions and become completely unattractive to young people. There is a threat to the development of public good and the complete depopulation of the regions. One of the most important strategic goals of the bioeconomy should be the creation of new jobs, the convergence of work and living places, the management of geographical mobility of the workforce, the strengthening of the competitiveness of rural regions.

Sustainability should be considered as part of the long-term time dimension in the assessment of food security (Berry et al., 2015), managing natural resources and others factors. Sustainability, which generally defined as the ability to meet the needs of the present without compromising the ability of future generations to meet their own needs, can be achieved through the development of the bio-economy. So, bioeconomy is here to stay. It is much more than just biomass-based production or biotechnology. Bioeconomy is a societal strategy to combat climate change and the increasing scarcity of natural resources (Luoma, Vanhanen, \& Tommila, 2011).

Without integrating sustainability as an explicit dimension of food security (Berry et al., 2015), managing natural resources, today's policies and programmes could become the very cause of increased food insecurity in the future. To modify program design and practice in ways that help to realize the great potential of bioeconomy, the stakeholders can overcome four levels of cooperation: information, consultation, joint action, collective decision-making.

Two key messages came from A. Wijering (2017), the member of Standing Committee of agriculture research (SCAR), during the presentation about contribution to stimulate the bioeconomy: balanced attention is required for all the (knowledge) demands in the bioeconomy. As areas influence each other, this demands an integrated systems approach; the added value of the bioeconomy lies in the interaction of the bioeconomy areas providing opportunities for new innovation (Langeveld, 2015).

Collaboration can help achieve outcomes that might otherwise be impossible. To do so, collaboration requires effort to nurture human relationships. People represent organizations, agencies, or occupations, but they are fundamentally human beings. 'The situation of two or more people working together to create or achieve the same thing' (Cambridge Dictionary) can be defined as collaboration. According to B. Gazley, J. Brudney (2007), collaboration is a 'process by which organizations with a stake in a problem seek a mutually determined solution pursuing objectives they could not achieve working alone'.

Cooperatives are people-centred enterprises owned, controlled and run by and for their members to realise their common economic, social, and cultural needs and aspirations. The concepts of bioeconomy development require the integration of different sectors and economic activities that can be achieved through regional/cross-border cooperation. However, cooperative stakeholders need to have confidence and responsibility and accountability. Cooperation is a form of business where two or more people share ownership, the responsibility for managing the company and the income or losses the business generates. That income is paid to partners, who then claim it on their personal tax returns - the business is 
not taxed separately, as corporations are, on its profits or losses.

According to scientists (Boardman, 2009; Brostrom, 2008; Chen, Yen - Chun Jim, \& WenHsuing, 2013), the main motives for co-operation are the following: benefits, belief in the value of collaboration and the importance of teamwork, continuous improvement, at the same time creating and sharing knowledge, pursuing prosperity using the available potential, etc. N. Miginis and M. Ulozas (2014) describe it as complementary cooperation between government, state institutions (health, education, environment, culture, sport, etc.), society, non-governmental organizations, business and media. The scientists distinguish the following essential features of cooperation:

- It is a well-defined and complementary cooperation between two or more sectors, but brings together as many stakeholders as possible for joint actions cooperation, added value creation;

- The sectors combine activities, ensure effective communication, resource use and leadership;

- Inter-organizational cooperation based on the set goals that aim to form a systematic, consistent and effective interaction.

It can be assumed that co-operation is a process in which cooperating actors seek a common mission, goals and efforts to achieve them. The end result, the value created by the actors is most satisfying. In the context of the development of bioeconomy, organizations are pooled to form joint activities, share activities, share resources, build capacity, and create new added value for all stakeholders and at the same time for society.

R. Bosman, J. Rotmans (2016) made the comparison analyses of Finland and the Netherlands on transition governance towards a bioeconomy. They found out, that in Finland and Netherlands it is very important to stimulate 'hybrid collaboration between agile and risk-taking niches (start-ups, small and medium enterprises), and risk-aversive elephants (traditional big companies), could be fruitful in accelerating the transition'.

S. Holtinger, M. Weigl (2017) made research in Central, East and South-East Europe, in particularly the Danube regions, and conclude, that the region could have a competitive advantage by shifting to bioeconomy as a comprehensive, innovative and sustainable economic paradigm. This would give an impulse to wide-ranging modernization, with positive impacts on economic growth, job creation, rural development, environment, etc. But the main barrier and weakness was identified 'lack of coordination among stakeholders, a limited access to finance, infrastructural weaknesses and depletion, instable regional/cross-border cooperation among stakeholders' (Holtinger \& Weigl, 2017). W.C Clarka, P. Thomas, T.P. Tomichb, M. Van Noordwijkc, D. Gustond, D. Catacutane, \& E. McNief (2016) made research of boundary work for sustainable development and conclude that especially important are arrangements regarding participation of stakeholders, accountability in governance, and the use of 'boundary objects'. The improving the ability of research programs to produce useful knowledge for sustainable development will require both greater and differentiated support for multiple forms of boundary work.

There are issues in Russian bioeconomy, which needed to be considered. Law does not fix the content of biofuel in gasoline. Only biofuels based on agricultural crops counted). It is recommended to correct these flaws. Biogas production is not industrial, not supported by law (stimulated by the need for waste disposal). Producing pellets with the adjusted production and the abundance of raw materials, Russian large manufacturers under load their production capacity and manufactured products are exported. It is recommended to establish infrastructure for internal use of pellets. Solid fuel (wood and peat pellets) is a full-fledged, marketable product that has not high demand in Russia, but is in demand among foreign consumers (Kudryavceva et al., 2016).

In the study assumed that the bioeconomy has the potential to improve the living conditions of farmers, foresters and other stakeholders - by cooperation and creating additional outlets for higher value-added products as well as promoting innovation in the primary sector. There are four levels of cooperation between farmers: information, consultation, joint action, collective decision-making. A bio-based economy is a new way of thinking of how to live in a sustainable way.

\section{Results and Discussion}

The challenges and relevant strategies for the cooperation in Kazakhstan. Cooperation within farmer's time to time attracts attention from state authorities and then become in the priorities list of agricultural reforms. In connection with the need to regulate production relations in agriculture, the first law on agricultural cooperation called 'About Production Cooperative' was issued in 1995. The number of agricultural cooperatives increased up to 2540 in 1995 from 487 in 1994.

New Law on Agricultural Cooperatives entered into force in 2016. According to it, the cooperatives in the agriculture of Kazakhstan operate in the form of a production cooperative and become commercial. The main players were supposed to be house holdings and small business (farmers). Until January 2016 all cooperatives in agriculture were non-commercial. 


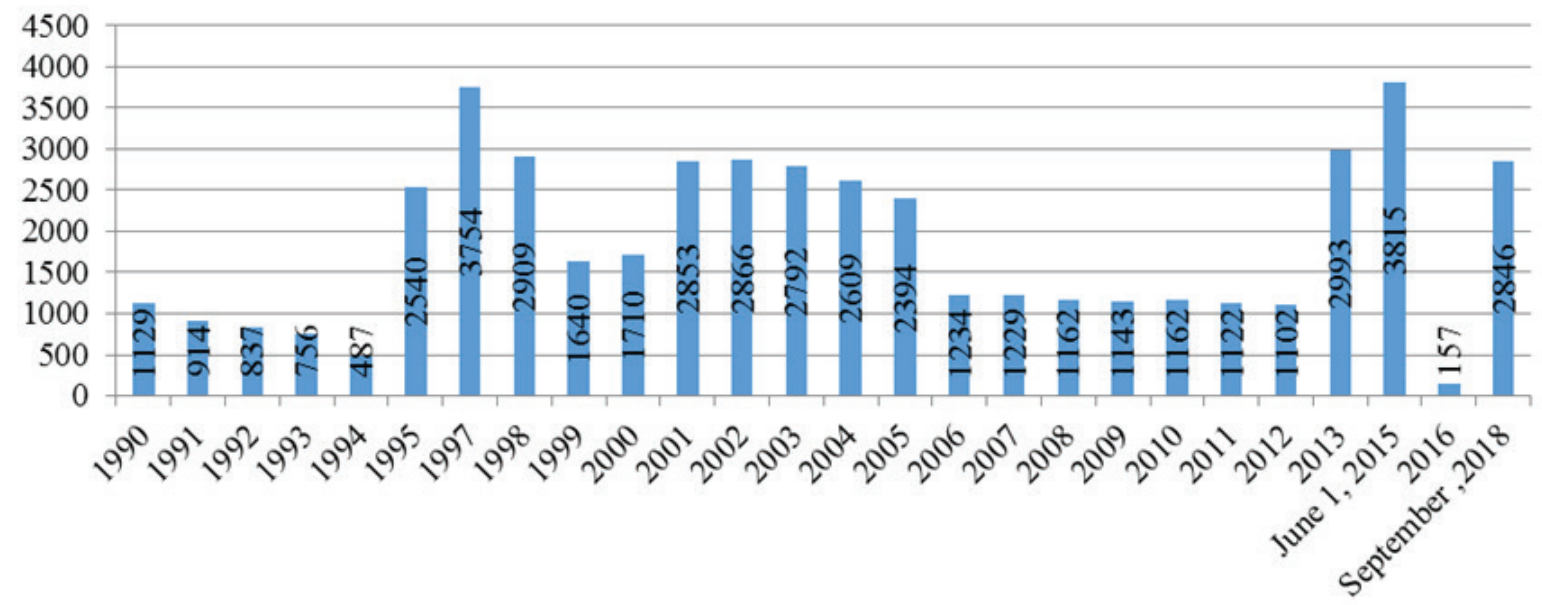

Figure 1. Number of operating agricultural cooperatives in Kazakhstan, September 1, 2018. Number of Agricultural Cooperatives in Kazakhstan

Source: Official website of Statistics Committee of the Ministry of national Economy of the Republic of Kazakhstan. Note: in 2016 only a number of new cooperatives launched under New law.

According to incomplete data, in 2015 there were 3,815 cooperatives of different types in rural areas, which after the adoption of the new law had to be reorganized into one type of agricultural cooperative agricultural producer co-operative, where agricultural cooperative can engage in various types of economic activities. Thus, in Kazakhstan there are agricultural cooperative, formed earlier, having some work experience and new agricultural cooperative, mainly dairy and meat directions, formed after enacting the new law.

Since 2017, the national statistics authorities have started to keep separate records on agricultural cooperatives with the following data: the number of agricultural co-operative and their members; unit trust; number of employees; production, purchase, sale, procurement of products; provision of services; availability of agricultural machinery; the presence of livestock and poultry.

In the first half of 2018 in Kazakhstan, 2872 agricultural cooperatives are registered. $43 \%$ of them operate in livestock. The number of entities increased 1.3 times in comparison to previous year.

The number of agricultural cooperatives increased during 2018 to $5 \%$. The main regions united in agricultural cooperatives are Turkestan, Eastern Kazakhstan, Akmola, Western Kazakhstan, Kyzylorda and Almaty representing total 67\%. Due to unfavourable climatic conditions in Mangystau and Atyrau oblasts, the agricultural sector is poorly developed, and therefore the number of employees in agricultural cooperatives is insignificant compared to other regions.

The main specialization of cooperatives is milk and meat direction of livestock (42\%), seasonal cultivation $(7 \%)$.
However, as announced by First Vice-Minister of Agriculture of Kazakhstan, 42\% of those registered cooperatives created formally, $18 \%$ are virtually inactive. According to new agricultural reforms, since 2016 state authorities propose to maintain three measurable key indicators with an annual growth of at least $10 \%$. This is:

- the growth of labour productivity of all the participants of cooperatives,

- the growth of revenue from sales of products, including from exports, as well as

the growth of investments in fixed assets, for example, for the purchase of agricultural equipment. (Report of the First Vice-Minister of Agriculture Evniev A.K., 2018).

The welfare of their cooperative can be tracked online. The Ministry of Agriculture is launching a special portal for monitoring the key indicators for agricultural cooperatives.

Although the number of agricultural cooperatives has increased since state initiatives the share of planned key participants such as individual house holdings is still low presenting as their members only $29073(1.6 \%)$ house holdings and 27399 farmers $(14.9 \%)$ at the beginning of 2018. Share of entities cooperated is $3.7 \%$. State budget spent $4.7 \mathrm{M}$ USD or $2 \%$ on subsidies to agricultural cooperatives. From 2020 subsidies will be given only entities not individual farmers. It is believed that it triggers farmers to enter cooperatives. Agricultural cooperatives are considered to be of horizontal and vertical (cluster) types. In Kazakhstan so far horizontal cooperatives are registered, but vertical cooperation still needs to be established.

In general, it can be said that small-scale agricultural commodity producers understand the 
need for cooperation, but due to psychological factors, they do not dare to unite into cooperatives. Despite the fact that a number of government measures have been developed to support agricultural cooperation, the indecisiveness of all respondents does not diminish (Balkibayeva \& Orazbayeva, 2012).

Over time, the opinion of the farmers is changing. When we re-surveyed a group of farmers, it is necessary to emphasize that the level of awareness turned out to be higher: farmers are interested in receiving comprehensive information about cooperation from various sources. At the same time, they are interested not only in theoretical aspects of the activities of cooperatives, but also in domestic and foreign experience in agricultural cooperation. One of the positive aspects is that some farmers are already in agricultural cooperation.

According to the results of the audit by the Presidential Administration in 2018, a number of systemic problems were identified that hinder the effective development of agricultural cooperation. This is a large proportion of inactive $(18 \%)$, and formally created cooperatives (42\%). Within problems facing by agricultural cooperatives were founded such as problems with processing and marketing of products manufactured by members of cooperatives, insufficient measures to stimulate the development of cooperatives, lack of agricultural land as well as the discrepancy of local authority (akimat's) data with official statistic data. According to analytical data of Ministry of agriculture the main limiting factors were: low level of explanatory work and lack of state support measures. Due to the low level of information work and the practical lack of propaganda of positive experience, there is a lack of understanding of the goals, principles and processes of cooperation on the ground. Often there is a formal creation of cooperatives as means to gain access to concessional loans (Ministry of Agriculture of Kazakhstan, 2015).

Ministry of Agriculture in 2015 updated the current state program, where 6 key problems of the agro industrial complex have been identified, the solution of which is facilitated by agricultural cooperation. There are: low labour productivity; low competitiveness of products, as a result - the lack of loading of processing enterprises; low technical equipment; lack of knowledge; low yield from sales of products; high overhead costs.

Insufficient amount of preferential credit resources from the republican budget to support established rural consumer cooperatives, also lead to negative reactions to co-operate between small commodity producers.

The networks and platforms for the needs of bioeconomy development in Kazakhstan. In Kazakhstan agricultural units like community type are organized mostly by sectors of agricultural economy, for instance Poultryman union, Meat Union, Potato producers Union, Farmers Union, Dairy Union etc. National Chamber of entrepreneurs registered in 2015 is considered as very active non government organization which united all entrepreneurs despite of industry.

National Union of Agricultural Cooperatives was established in 2017, but currently it has stopped its operation. The reason is agricultural cooperatives support was stopped by new Ministry of agriculture.

Farmers Union as non government unit to cooperate farmers was established in 2003. Over 10, 000 farmers are members (5\%) of Farmers Union. The main aim of the organization is to support farmers, represent their interests and rights.

More than a half of rural NGOs in Kazakhstan $(53.8 \%)$ represent small organizations, the number of staff of which is not more than 3 persons. The biggest proportion of such large-scale rural NGOs we can see in southern region $(39.1 \%)$ what is determined by the largest part of rural population in Kazakhstan living there ( $60 \%$ by the beginning of 2004), as well as by the lowest living standards in that region of the country (Saktaganova, \& Ospanova, 2013).

There are State Enterprise, business and governmental organizations, which act in the interdisciplinary cooperation. State Enterprise 'National Center for Biotechnology' (NCB) the country's leading biological center supports bioeconomy aims and plays an important role, implementing the State policy on support and development of biotechnology industry - was founded in 1993. The center implements and coordinates the government-funded scientific - technical programmes in the field of biotechnology, biosafety and ecology.

As part of cooperative projects NCB cooperates with other structures in the form of 4 consortiums:

- The Corporate Research Center for Biopreparations and Vaccines Production. Based on 'BIOTRON GROUP' LLP there are established scientific laboratories of NCB for development and production of new biotechnology products.

- The Eurasian Biomedical Technology Platform (2014). The Consortium members: on part of the Russian Federation - Noncommercial Partnership 'Technology Platform "Medicine of the Future", on part of the - SI 'Belarusian Institute of System Analysis and Information Support of Scientific and Technical Sphere', on part of the Republic of Kazakhstan - BCB. The Consortium is a permanent coordinating and advisory body formed to organize effective interaction of research, educational, industrial and other organizations on the issues of preparation 
and implementation of projects in the field of biomedicine.

- The Eurasian Biotechnology

Platform. Members are Russia, Belorussia and Kazakhstan. The Consortium is a permanent coordinating and advisory body formed to multiply the creative and technical capabilities of its members. All of the biotech community of the Eurasian Economic Commission member states, by means of concentration of intellectual and administrative resources of the states, businesses, educational institutions and non-governmental organizations aimed at development and effective use of biotechnology for benefit of science, education, industries, social and public needs.

- The Innovative-Educational Consortium 'Biotechnology'. The Consortium members are NCB and Kazakhstani universities (National Center for Biotechnology, 2019).

The interviewed farmers knew little about innovative centers and platforms. Key factors have been identified that limit cooperation: the insufficient information on the procedure of creating cross sectorial cooperatives, platforms; lack of motivation and knowledge how to participate in the State Enterprise 'National Center for Biotechnology' activities; lack of qualified middle-level specialists as consultants; the difference in the life values of individual farmers.

\section{Conclusions}

1. Agricultural cooperatives of Kazakhstan have a very small share in the market and their activities are usually focused on sales of the raw material rather than on processing and marketing. After new Ministry team, coming no further support was given to promote agricultural cooperatives movements. A result, the number of formed cooperatives is decreasing. National Union of Agricultural Cooperatives was established in 2017 , but currently stopped its operation due to the above-mentioned reason.

2. Representing Kazakhstan farmers' organizations, the role of the farmers' organizations in self- government does not work on the principles of self-organization. The further steps of municipal organizations, uniting farmers, are strengthening the representation of the farmers, positive selfimage and larger increase in the number of the members.

3. The cooperation within farmers (horizontal cooperation) is so far narrow and limited to traditional cooperatives that bring together producers of the same product. New forms of cooperation and more diverse directions in national, regional and local levels are needed to develop the bioeconomy. It is time and place to be integrative and complex for either individual farmers or enterprisers and other members of agro industrial complex.

4. The analysis of scientific literature, the strategic provisions of the European Union countries and the small experience of Kazakhstan have shown that cooperation plays a major role in the development of the bioeconomy.

5. There are business organizations in Kazakhstan that plan to develop their activities according to the principles of bioeconomy. In order to achieve the bioeconomy potential, primary producers need to play a more active role in the value creation of the bioeconomy supply chains. The agricultural and rural development advisory system should be improved, and new measures to promote communication, counseling and cooperation should be introduced.

6. Partnerships, the interdepartmental and interdisciplinary cooperation based on knowledge and innovation should be established between farmers, agri-food companies and scientific institutions, Kazakhstan and other countries universities.

7. As financial assistance, we consider it possible to provide grant funding for projects that are breakthrough in their significance and scope for the development of the bioeconomy, in which agricultural producers, cooperatives, and other organizations participating in the "researchproduction-sales" chain will be involved.

\section{References}

1. Balkibayeva, A., \& Orazbayeva, A.C. (2012). О развитии сельской потребительской кооперации в Казахстане (About rural consumer cooperation development in Kazakhstan). Science Bulletin S. Seifullin Kazakh Agrotechnical University, No. 2(73), pp. 69-73. (in Russian)

2. Berry, E.M., Dernini, S., Burlingame, B., Meybeck, A., \& Conforti, P. (2015). Food security and sustainability: can one exist without the other? Public Health Nutrition, Vol. 18, Issue 13, $2293-2302$. DOI: $10.1017 / \mathrm{S} 136898001500021 \mathrm{X}$.

3. Boardman, P.C. (2009). Government Centrality to University-Industry Interactions: University Research Centers and the Industry Involvement of Academic Researchers. Research Policy. pp. 1505-1516.

4. Bosman, R., \& Rotmans, J. (2016). Transition Governance towards a Bioeconomy: A Comparison of Finland and The Netherlands. Sustainability, No. 8, pp. 2-20. 
5. Broström, A. (2008). Firms' Rationales for Interaction with Research Universities and the Principles for Public Co-Funding. CESIS. Electronic Working Paper Series. pp. 313-329.

6. Holtinger, S., \& Weigl, M. (2017). Position Paper: for the development of bioeconomy in the Danube region. Budapest-Trieste. Retrieved February 11, 2019, from https://danube-inco.net/object/document/18543/ attach/Position_Paper_Towards_a_Danube_bioeconomy_RTI_strategy.pdf .

7. Chen, C.Y., Yen-Chun Jim, Wu, \& Wen-Hsuing, Wu (2013). A Sustainable Collaborative Research Dialogue between Practitioners and Academics. Management Decision.

8. Clarka, W.C., Thomas, P., Tomichb, T.P., Van Noordwijkc, M., Gustond, D., Catacutane, D., \& McNief, E. (2016). Boundary work for sustainable development: Natural resource management at the Consultative Group on International Agricultural Research (CGIAR) PNAS, Vol. 113, No. 17, pp. 4615-4622. DOI: 10.1073/pnas.0900231108.

9. EU bioeconomy strategy. (2012). A sustainable bioeconomy for Europe: strengthening the connection between economy, society and the environment. European Commission, Brussels. Retrieved February 15, 2019, from https://ec.europa.eu/research/bioeconomy/pdf/ec_bioeconomy_strategy_2018. pdftuiew $=$ fit\&pagemode $=$ none.

10. European Commission. (2012). Innovating for Sustainable Growth: A Bioeconomy for Europe. COM (2012) final, European Commission, Brussels, Belgium.

11. Food and Agriculture Organization of the United Nations (1996). Rome Declaration on Food Security and World Food Summit Plan of Action. Rome: FAO.

12. Gazley, B., \& Brudney, J. (2007). The Purpose (and Perils) of Government-Nonprofit Partnership. Nonprofit and Voluntary Sector Quarterly No. 36, pp. 389-415.

13. Langeveld, J.W.A. (2015). Results of the JRC-SCAR bioeconomy survey January 2015). Wageningen, The Netherlands. Retrieved February 11, 2019, from https://www.scar-swg-sbgb.eu/lw_resource/datapool/ items/item_24/survey_bioeconomy_report1501_full_text.pdf.

14. Lindner, M. ., Hanewinkel, M., \& Nabuurs, G. (2017). How can a forest-based bioeconomy contribute to climate change adaptation and mitigation? What Science Can Tell Us, 8, European Forest Institute, pp. 77-85.

15. Lithuanian Bioeconomy Development Feasibility Study. (2017). Akademija, Kauno r.

16. Luoma, P., Vanhanen, J., \& Tommila, P. (2011). Distributed Bio-Based Economy: Driving Sustainable Growth; SITRA: Helsinki, Finland. Retrieved March 3, 2019, from https://media.sitra.fi/2017/02/23070426/ Distributed_BioBased_Economy-7.pdf.

17. McCormick, K., \& Kautto, N. (2013). The Bioeconomy in Europe: An Overview. Sustainability, 2013, 5(6), 2589-2608. DOI: 10.3390/su5062589.

18. Miginis, N., \& Ulozas, M. (2014). Tarpžinybinis bendradarbiavimas nacionaliniu lygmeniu. Jaunimo politikos srityje (Interagency cooperation at national level. In the field of youth policy). Retrieved March 1, 2019, from http://ijpp.lt/file/TB_ANALIZE.pdf. (in Lithuanian)

19. National Center for Biotechnology. (2019). Consortiums. Retrieved March 12, 2019, from http://www. biocenter.kz/en/collaboration/consortiums.

20. Official website of Statistics Committee of the Ministry of national Economy of the Republic of Kazakhstan. Retrieved March 12, 2019, from www. stat.gov.kz.

21. Philippidis, G., M'barek, R., \& Ferrari, E. (2016). Drivers of the European Bioeconomy in Transition (BioEconomy 2030) - an exploratory, model-based assessment: Publications Office of the European Union. Retrieved March 12, 2019, from https:/ec.europa.eu/jrc/en/publication/eur-scientific-andtechnical-research-reports/drivers-european-bioeconomy-transition-bioeconomy2030-exploratory-modelbased-assessment.

22. Saktaganova, Z.G., \& Ospanova, D.K. (2013). Non-Governmental Organizations in the Republic of Kazakhstan: Principle Stages of Formation and Development. Middle-East Journal of Scientific Research, $15(9), 1277-1284$.

23. Wijering, A. (2017). SCAR contribution to stimulate the bioeconomy. SCAR Standing Committee of agriculture research. Retrieved March 3, 2019, from https://www.scar-swg-sbgb.eu/lw_resource/ datapool/_items/item_22/bioeconomy-talk-scar.pdf.

24. Государственная программа развития АПК РК на 2017-2021 (State program of development of agro industrial complex of Kazakhstan for 2017-2021). (2016). Retrieved March 1, 2019, from https://moa.gov. $\mathrm{kz} / \mathrm{ru}$ /documents/1. (in Russian)

25. Доклад Первого вице-Министра сельского хозяйства А.К. Евниева о развитии сельскохозяйственных кооперативов (Report of the First Vice-Minister of Agriculture Evniev A.K. on the development 
of agricultural cooperation). May 29, 2018. Retrieved March 1, 2019, from http://mgov.kz/ru/auylsharuashyly-y-kooperatsiyasyn-damytu-m-selesi-bojynsha-auyl-sharuashyly-y-birinshi-vitse-ministri-a -evnievti-bayandamasy/. (in Russian)

26. Закон о сельскохозяйственных кооперативах (Law on Agricultural Cooperatives). (2015). (in Russian)

27. Кудрявцева, О.В., Бобылев, С.Н., Кирюшин, П.А. и др., (2016). Биоэкономика России: возможности развития (The Bioeconomy of Russia. The development perspectives). Москва: Проспект. 176 с. (in Russian)

28. Минсельхоз РК: 18\% всех кооперативов бездействуют (Ministry of Agriculture of the Republic of Kazakstan:18\% of all cooperatives is not active). (2018). Retrieved March 1, 2019, from https://24.kz/ru/ news/economyc/item/243226-minselkhoz-rk-18-vsekh-kooperativov-bezdejstvuyut. (in Russian) 